The maximum measured concentration of $\mathrm{Pu}$ at the ER-20-5 site is $\sim 10^{-14} \mathrm{M}$. This value is lower than the solubility limits of $\sim 10^{-}$ ${ }^{8} \mathrm{M}$ that have been experimentally determined for the $\mathrm{Pu}(\mathrm{v})$ species likely to be present in NTS ground water ${ }^{4}$. The calculated solubility limits $\left(10^{-12}-10^{-17} \mathrm{M}\right)$, obtained by assuming that $\mathrm{Pu}(\mathrm{IV})$ is in thermodynamic equilibrium ${ }^{26,27}$, bracket the maximum measured $\mathrm{Pu}$ concentration. It thus seems that the $\mathrm{Pu}$ concentrations in the ground water at ER-20-5 were too low to lead to the precipitation of a solid $\mathrm{Pu}$ phase. Our results indicate that $<1 \%$ of the observed $\mathrm{Pu}$ is in the dissolved fraction of the ground water. This finding and the previously reported results of $\mathrm{Pu}$ sorption experiments ${ }^{4,5}$ are most consistent with $\mathrm{Pu}$ migrating as colloidal material and not as a dissolved phase. The concentration of $\mathrm{Pu}$ measured is small, and represents only a small fraction of the total $\mathrm{Pu}$ associated with the Benham nuclear test.

Based on 40 years of re-drilling underground nuclear test cavities and collecting melt glass samples for test diagnostics, it has been observed that the majority ( $\sim 98 \%$ ) of the refractory radionuclides (such as $\mathrm{Pu}$ ) are incorporated into the melt glass that forms at the bottom of the test cavity ${ }^{12,28}$. In field studies where ground water can be eliminated as a possible transport mechanism, radionuclides were detected at a maximum of a few hundred metres from the original detonation point, and were attributed to gas movement through fractures, or fracture injection of vaporized material at detonation time ${ }^{29,30}$. The possibility that $\mathrm{Pu}$ from the Benham test site was blasted and deposited $>1.3 \mathrm{~km}$ away, in two distinct aquifers separated by $300 \mathrm{~m}$ vertically and $30 \mathrm{~m}$ horizontally, seems highly unlikely. However, some fraction of the $\mathrm{Pu}$ may have been initially injected through fractures a few hundred metres and subsequently transported by ground water.

Molbo, Belmont and Tybo nuclear tests were all detonated after Benham. Although shock waves resulting from underground nuclear blasts can induce radial fractures out to a maximum distance of a few hundred metres (ref. 30), it is unlikely that these detonations blasted material from Benham to ER-20-5, as they were all smaller detonations and by inference shallower. In addition, $\mathrm{Pu}$ from these subsequent three tests was not detected in the ground water at ER-20-5.

The high pumping rates $\left(0.03 \mathrm{~m}^{3} \mathrm{~min}^{-1}\right)$ employed may create shear stresses sufficient to generate an increase in the concentration of colloids and thus prevent a quantification of the ambient colloidal load and, by inference, a determination of the minimum or maximum concentration of $\mathrm{Pu}$ in the ground water. But the isotope ratio of the $\mathrm{Pu}$ measured in ground water from ER-20-5 nevertheless clearly establishes that the radionuclide originates from a specific nuclear event, $\sim 1.3 \mathrm{~km}$ to the north. The present work thus demonstrates that $\mathrm{Pu}$ is not immobile in the subsurface, but can be transported over significant distances. Pu transport models that only take into account sorption and solubility may therefore underestimate the extent to which this species is able to migrate in ground water.

Received 24 February; accepted 6 October 1998

1. Degueldre, C. et al. Colloids in water from a subsurface fracture in granitic rock, Grimsel test site, Switzerland. Geochim. Cosmochim. Acta 53, 603-610 (1989).

2. McDowell-Boyer, L. M. Chemical mobilization of micron sized particles in saturated porous media under steady flow conditions. Environ. Sci. Technol. 26, 586-593 (1992)

3. Ryan, J. N. \& Elimelech, M. Colloid mobilization and transport in groundwater. Colloids Surfaces A: Physicochem. Eng. Aspects 107, 1-56 (1996).

4. Nitsche, H. et al. Measured Solubilities and Speciations of Neptunium, Plutonium, and Americium in a Typical Groundwater (J-13) from the Yucca Mountain Region Milestone Report 3010-WBS 1.2.3.4.1.3.1 (Rep. LA-12562-MS, Los Alamos National Laboratory, 1993)

5. Triay, I. R. et al. Radionuclide Sorption in Yucca Mountain Tuffs with J-13 Well Water: Neptunium, Uranium, and Plutonium (Rep. LA-12956-MS, Los Alamos National Laboratory, 1996).

6. Buddemeier, R. W. \& Hunt, J. R. Transport of colloidal contaminants in groundwater: radionuclide migration at the Nevada Test Site. Appl. Geochem. 3, 535-548 (1988).

7. Penrose, W. R., Polzer, W. L., Essington, E. H., Nelson, D. M. \& Orlandini, K. A. Mobility of plutonium and americium through a shallow aquifer in a semiarid region. Environ. Sci. Technol. 24, 228-234 (1990).

8. McCarthy, J. F. \& Degueldre, C. in Environmental Particles 2 (eds Buffle, J. \& van Leeuwen, H. P.) $247-$ 315 (Lewis, Ann Arbor, 1993).

9. Marty, R. C., Bennett, D. \& Thullen, P. Mechanism of plutonium transport in a shallow aquifer in
Mortandad canyon, Los Alamos National Laboratory, New Mexico. Environ. Sci. Technol. 31, 2020_ 2027 (1997)

10. United States Nuclear Tests_July 1945-September 1992 (DOE/NV-209 (Rev. 14), US Department of Energy/Nevada Field Office, 1994).

11. Smith, D. K. Characterization of nuclear explosive melt debris. Radiochim. Acta 69, 157-167 (1995). 12. Borg, I. Y., Stone, R., Levy, H. B. \& Ramspott, L. D. Information Pertinent to the Migration of Radionuclides in Ground Water at the Nevada Test Site (Rep. UCRL-52078, Lawrence Livermore National Laboratory, 1976).

3. Blankennagel, R. K. \& Weir, J. E. J. Geohydrology of the eastern part of Pahute Mesa, Nevada Test Site, Nye County, Nevada Geol. Surv. Prof. Pap. 712-B (1973).

14. Laczniak, R. J., Cole, J. C., Sawyer, D. A. \& Trudeau, D. A. Summary of Hydrogeologic Controls on Ground-Water Flow at the Nevada Test Site, Nye County, NV (Rep. 96-4109, US Geological Survey, 1996).

15. Perrin, R. E., Knobeloch, G. W., Armijo, V. M. \& Efurd, D. W. Isotopic analysis of nanogram quantities of plutonium by using a SID ionization source. Int. J. Mass Spectrom. Ion Phys. 64, 17-24 (1985).

16. Thompson, J. L. Laboratory and Field Studies Related to radionuclide Migration at the Nevada Test Site October 1, 1996-September 30, 1997 (Rep. LA-13419-PR Ed., Los Alamos National Laboratory, 1998).

17. Smith, D. K. et al. Hydrologic Resources Management Program and Underground Test Area Operable Unit FY 1997 Progress Report (Rep. UCRL-ID-130792 Ed., Lawrence Livermore National Laboratory, 1998)

18. Broxton, D. E., Bish, D. L. \& Warren, R. G. Distribution and chemistry of diagenetic minerals at Yucca Mountain, Nye County, Nevada. Clays Clay Miner. 35, 89-110 (1987).

19. Bates, J. K., Bradley, J. P., Teetsov, A., Bradley, C. R. \& Buchholtz ten Brink, M. Colloid formation during waste form reaction: implications for nuclear waste disposal. Science 256, 649-651 (1992).

20. Viani, B. E. \& Martin, S. I. Groundwater Colloid Characterization (UCRL-Lawrence Livermore National Laboratory, 1996).

21. Kingston, W. L. \& Whitbeck, M. Characterization of Colloids Found in Various Groundwater Environments in Central and Southern Nevada (Rep. DOE-NV/10384-36, Desert Research Inst., Las Vegas, 1991).

22. Comans, R. N. J. \& Hockley, D. E. Kinetics of cesium sorption on illite. Geochim. Cosmochim. Acta 56, 1157-1164 (1992).

23. Torstenfelt, B., Rundberg, R. S. \& Mitchell, A. J. Actinide sorption on granites and minerals as a function of $\mathrm{pH}$ and colloids/pseudocolloids. Radiochim. Acta 44/45, 111-117 (1988).

24. Triay, I. R., Lu, N., Cotter, C. R. \& Kitten, H. D. Iron Oxide Colloid Facilitated Plutonium Transport in Goundwater (Am. Chemical Soc., Las Vegas, 1997).

25. Silva, R. J. \& Nitsche, H. Actinide environmental chemistry. Radiochim. Acta 70/71, 377-396 (1995)

26. Stout, R. B. \& Leider, H. Preliminary Waste Form Characteristics Report Version 1.0 (Rep. UCRL-ID108314 Rev. 1, Lawrence Livermore National Laboratory, 1994).

27. Guillaumont, R. \& Adloff, J. P. Behavior of environmental plutonium at very low concentrations Radiochim. Acta 58/59, 53-60 (1992).

28. Levy, H. B. On Evaluating the Hazards of Groundwater Contamination by Radioactivity from an Underground Nuclear Explosion (Rep. UCRL-51278, Lawrence Livermore National Laboratory, 1972).

29. Nimz, G. J. \& Thompson, J. L. Underground Radionuclide Migration at the Nevada Test Site (Rep. DOE/ NV-346, US Department of Energy, Nevada Field Office, 1992).

30. Smith, D. K., Nagle, R. J. \& Kenneally, J. M. Transport of gaseous fission products adjacent to an underground nucelar test cavity. Radiochim. Acta 73, 177-183 (1996).

31. Hudson, B. C., Jones, E. M., Keller, C. E. \& Smith, C. W. Cavity Radius Uncertainties (Rep. LA-9211-C, Los Alamos National Laboratory, Monterey, 1981).

Acknowledgements. We thank B. A. Martinez, F. R. Roensch, J. W. Chamberlin and G. P. Russ for help with sample analysis, and I. R. Triay, B. E. Viani, R. W. Lougheed, H. F. Shaw, F. J. Ryerson, J. F. Wild and G. B. Hudson for discussions. This work was funded partly by the Underground Test Area Project sponsored by US Department of Energy, Nevada Operations Office. Work was performed under the auspices of the US Department of Energy by Los Alamos National Laboratory and Lawrence Livermore National Laboratory.

Correspondence and requests for materials should be addressed to A.B.K. (e-mail: Kersting@llnl.gov).

\section{Patterns of recruitment and abundance of corals along the Great Barrier Reef}

\author{
T. P. Hughes, A. H. Baird, E. A. Dinsdale, \\ N. A. Moltschaniwskyj ${ }^{\star}$, M. S. Pratchett, J. E. Tanner \\ \& B. L. Willis
}

Department of Marine Biology, James Cook University, Townsville,

Queensland 4811, Australia

Different physical and biological processes prevail at different scales $^{1-4}$. As a consequence, small-scale experiments or local observations provide limited insights into regional or global phenomena $^{5-8}$. One solution is to incorporate spatial scale explicitly into the experimental and sampling design of field studies, to provide a broader, landscape view of ecology ${ }^{1-8}$. Here we examine spatial patterns in corals on the Great Barrier Reef, across a spectrum of scales ranging from metres to more than $1,700 \mathrm{~km}$. Our study is unusual because we explore large-scale patterns of a

* Present address: Department of Aquaculture, University of Tasmania, Launceston, Tasmania 7250, Australia. 
process (recruitment by juveniles) as well as patterns of adult abundance, revealing the relationship between the two. We show that coral-reef assemblages that are similar in terms of abundance may nonetheless show profound differences in dynamics and turnover, with major implications for their ecology, evolution and management.

The continuous expanse of Australia's Great Barrier Reef (GBR) provides a unique opportunity for exploring the effects of scale dependency in marine systems. The GBR Marine Park is the largest underwater reserve in the world, stretching over $2,000 \mathrm{~km}$ and comprising some 2,500 individual reefs separated by distances ranging from a few hundred metres to tens of kilometres. Understanding patterns of recruitment among reefs by larvae is crucial for managing this system. Previous studies of coral recruitment on the $\mathrm{GBR}^{9}$ have been limited to adjacent sites or to very few reefs, and have used a variety of techniques that preclude statistical comparisons at larger scales. Here we measured rates of recruitment on 33 reefs that stretch from $10^{\circ}$ to $23^{\circ} \mathrm{S}$ (Fig. 1). We used a hierarchical sampling design ${ }^{10}$ to measure spatial variation in recruitment and adult abundance, at four scales spanning 5-6 orders of magnitude (Fig. 2). This approach provides a powerful framework for quantifying the proportion of the total variation among samples that is attributable to each spatial scale. We distinguish here between two ecologically distinct groups of corals: spawners and brooders. (Most corals on the GBR are spawners, that is, they release sperm and eggs simultaneously ${ }^{9,11}$. In contrast, brooders release fertilized larvae. The dominant brooders on the GBR are three species of Acropora in the subgenus Isopora, and eight species of Pocillopora, Seriatopora and Stylophora in the family Pocilloporidae.)

The density of recruits varied at all spatial scales for both spawners and brooders, with distinctive patterns occurring in each group. Recruitment by spawners varied by more than 25 fold among sectors in both years, compared with a more modest five- to eightfold variation for brooders (Fig. 3). In year 1, the two types of recruit were equally abundant at the northern- and southern-most sectors ( 1 and 6 , respectively), whereas spawners were 3-5 times more numerous elsewhere. In year 2, spawning recruits exceeded brooders in all sectors. For spawners, 52-55\% (depending

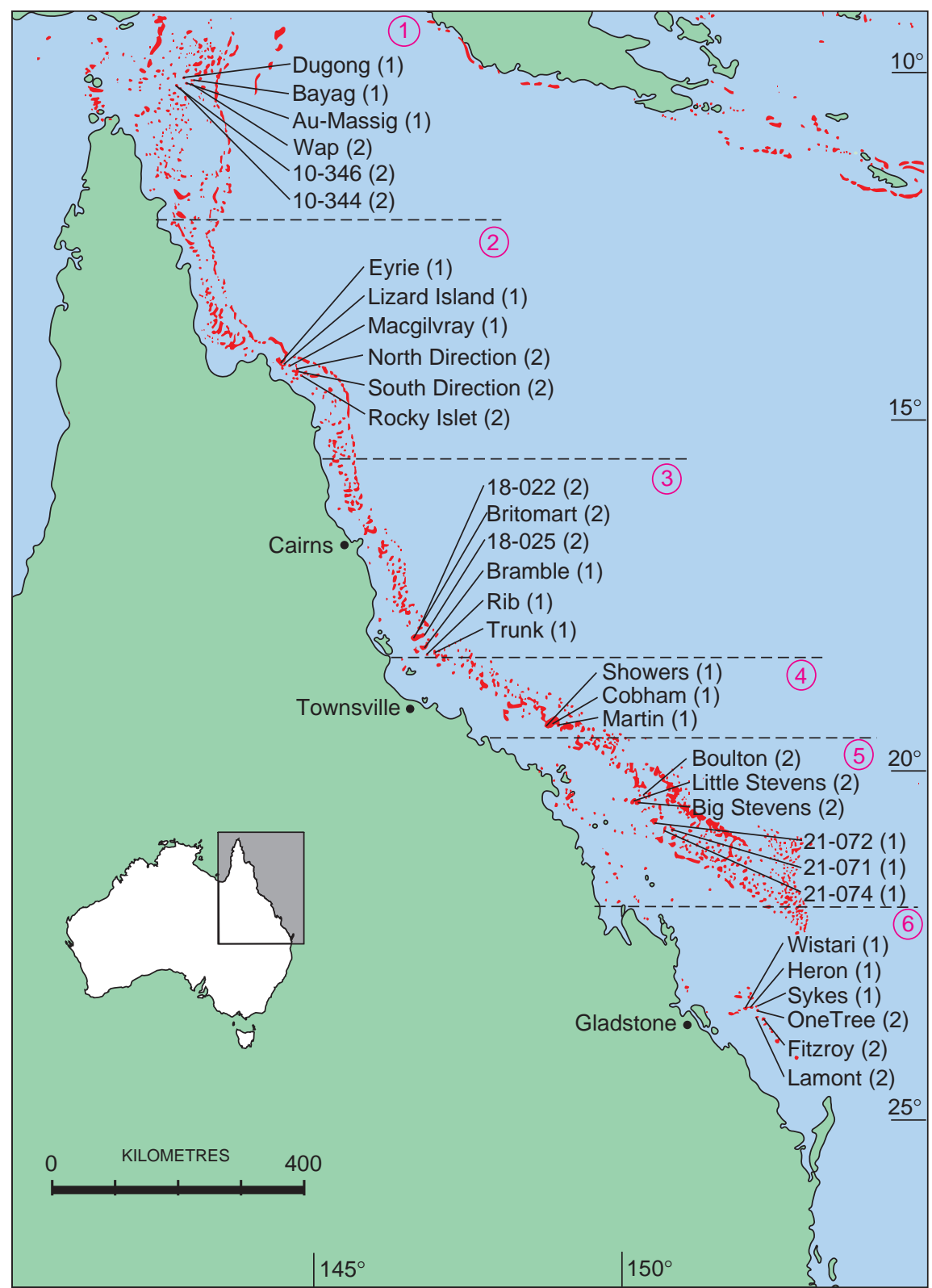

Figure 1 Map of the GBR, indicating the location of 33 reefs at which recruitment and abundance of corals were measured. Eighteen reefs in six sectors were sampled in 1995/6 (year 1), and a further 15 reefs in 1996/7 (year 2). Sectors of the GBR are numbered 1-6 from north to south. 
on year) of the variation in recruitment was attributable to the largest spatial scale (sector), reflecting the marked latitudinal differences in density (Fig. 4). In contrast, variability in recruitment by brooders among sectors accounted for only $25-29 \%$ of the total variation. Variability was low at the scale of adjacent reefs for both spawners and brooders $(0-6 \%$ of the total variation for spawners, and $3-13 \%$ for brooders). At smaller scales within reefs, variation increased once more: $21-22 \%$ and $25-36 \%$ of the total variation occurred among sites on a reef for spawners and brooders, respectively. Finally, variation among replicate panels within sites accounted for $18-26 \%$ of the total variation in spawners, compared with $32-36 \%$ in brooders. The partitioning of variation among spatial scales was highly consistent over two years for both spawners and brooders (Fig. 4), despite a threefold difference among years in the total amount of recruitment $(24.8 \pm 1.1$ (s.e.) recruits per panel in year 1 compared with $86.9 \pm 4.2$ recruits in year 2 ).

Recruitment by spawners varied most among sectors and least among reefs in both years (Fig. 4). This pattern is driven presumably by large-scale hydrodynamic or meteorological phenomena, such as the latitudinal gradient in water temperature along the east coast of Australia. At a much smaller scale, the mean number of recruits varied among sites by more than 200 -fold for spawners and 100 -fold

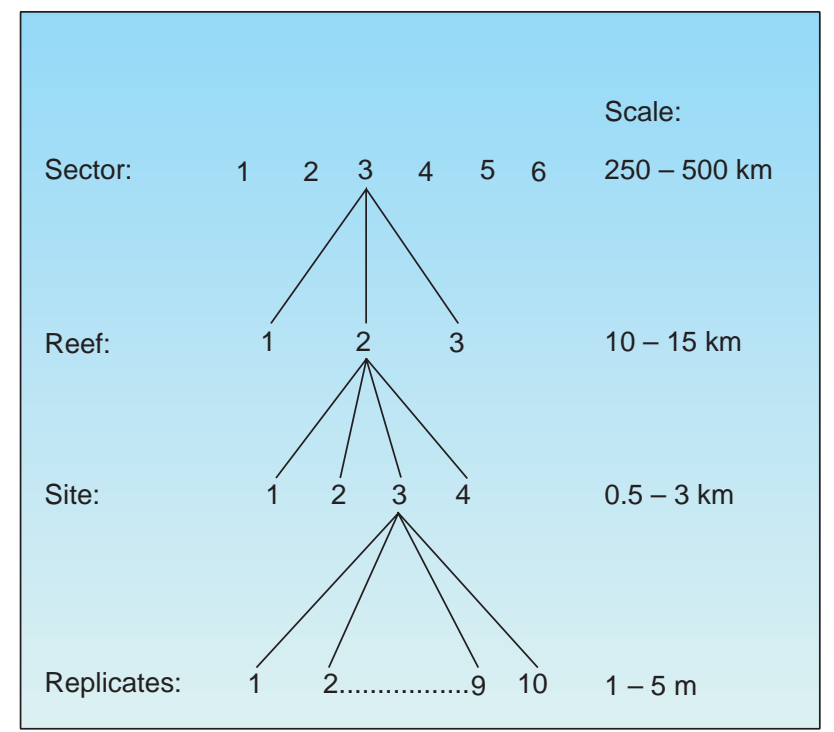

Figure 2 A hierarchical sampling design used to measure spatial variation in the recruitment and abundance of corals in sectors along the GBR, each 250-500 km apart. Within each sector, we selected three mid-shelf reefs at random, separated by $\sim 10-15 \mathrm{~km}$ (Fig. 1). On each reef, we chose four sites on the reef crest that were 0.5-3 km apart. Within-site variation at a scale of a few metres was measured among replicates (ten replicate panels for measuring recruitment, and ten 10-mlong transects for measuring adult abundance). Panels were deployed synchronously on mid-shelf reef crests (approximately $1 \mathrm{~m}$ below datum), ten days $( \pm 1)$ before the predicted annual mass-spawning of corals ${ }^{9,11}$, and retrieved eight weeks later. Panels were unglazed tiles $(11 \times 11 \mathrm{~cm})$ attached individually to the substratum by a bolt that held them $2-3 \mathrm{~cm}$ above the reef surface. Note that the panels were deployed on different reefs in separate years as our objective was to measure the effects of spatial scale rather than the predictability of recruitment at any particular site or reef. A total of 1,135 panels were relocated and recruits on their undersurface were counted. Juvenile corals were identified to family or genus where possible, and classified as spawners or brooders ${ }^{9}$. In year 1 , the abundance of adult spawning and brooding corals was measured using ten 10-mlong intercept transects, placed alongside the recruitment panels. All colonies were identified, counted and measured to the nearest centimetre. The number of recruits each year, cover of adults and the number of adults were analysed separately for spawners and brooders using a three-factor nested analysis of variance, with sectors, reefs and sites as random factors. Heterogeneity of variances was removed using log $(x+1)$ transformations. for brooders in all sectors in both years. This level of variation (see also Fig. 5) is unlikely to have been due to spatial variation in mortality after settlement, as the panels were exposed for only 8 weeks and there were few signs of predation or competitive interactions on them (particularly on the undersurfaces of panels where the recruits were counted). We propose therefore that most of the variation in patterns of recruitment (Fig. 4) occurred at the time of settlement, at both large and small scales. Furthermore, the greater variation among reefs and sites for brooders (39\% of the total variation in both years compared with $22-27 \%$ for spawners) is consistent with their generally shorter larval duration ${ }^{9}$ and lower levels of gene flow (refs 12-14 and D. J. Ayre and T.P.H., unpublished data).

Sectors, reefs, sites and panels that had large numbers of spawners did not necessarily receive large numbers of brooders (Figs 3, 5). Similarly, large-scale patterns of recruitment by reef fishes also differ among species ${ }^{15,16}$. These disparities have important implications for rates of re-colonization by different taxa after disturbances (for example, as a result of cyclones, mass bleaching or outbreaks of crown-of-thorns starfish), and for the design and management of coral-reef reserves. Clearly, sectors or reefs that are 'sources' or 'sinks' for one taxonomic group may show the opposite pattern for another, depending on factors such as stock size, larval duration, planktonic mortality, and settlement behaviour.

In contrast to patterns of recruitment, the abundance of adult spawning corals (number of colonies per transect) did not vary significantly among sectors or reefs (Fig. 3), with $91 \%$ of the total variation occurring among sites and among replicate transects (Fig. 4). Adult brooding corals varied threefold among sectors, accounting for $29 \%$ of the overall variation. As with spawners, the density of adult brooders did not differ significantly among adjacent reefs, and the remainder of the variation occurred at smaller scales. Spawners were more abundant than brooders in all sectors and on all reefs (Fig. 3). Nearly identical patterns were found for adult cover. These results show that the total abundance of adult spawning corals on reef crests along the GBR is relatively homogeneous among reefs and sectors, despite substantial differences in recruitment at large scales (Figs 3,4). The same pattern occurs at an oceanic scale: corals in the Caribbean Sea can achieve high adult numbers and cover that are comparable to the GBR, yet rates of recruitment there are $\sim 2$ orders of magnitude lower (typically $<1$ per panel after a few months ${ }^{17-19}$ ). The lack of conformity between adult abundance and recruitment implies that rates of post-recruitment survival are higher in geographic regions or sectors of the GBR

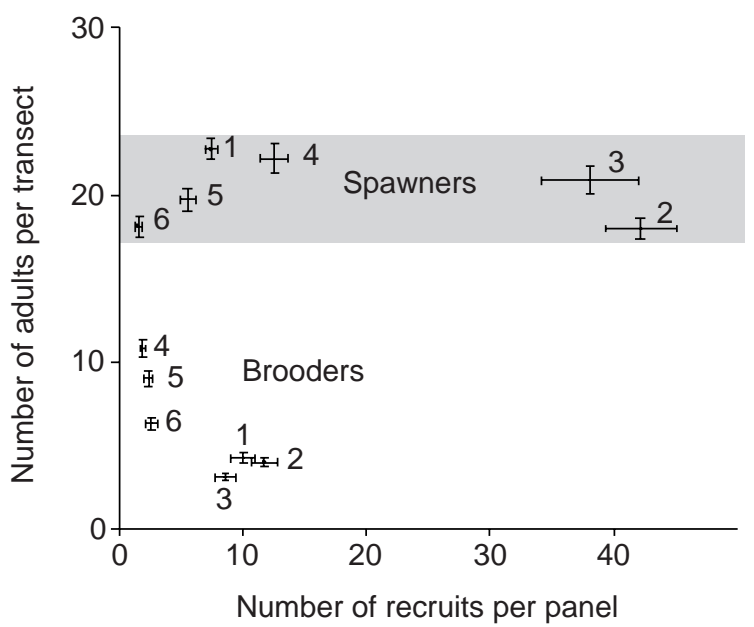

Figure 3 Amounts of recruitment (number per panel) and adult abundance (number of colonies per 10-m transect) of spawning and brooding corals on reef crests in six sectors of the GBR (numbered 1-6 from north to south, see Fig. 1). Error bars indicate one standard error among replicate panels and transects. 


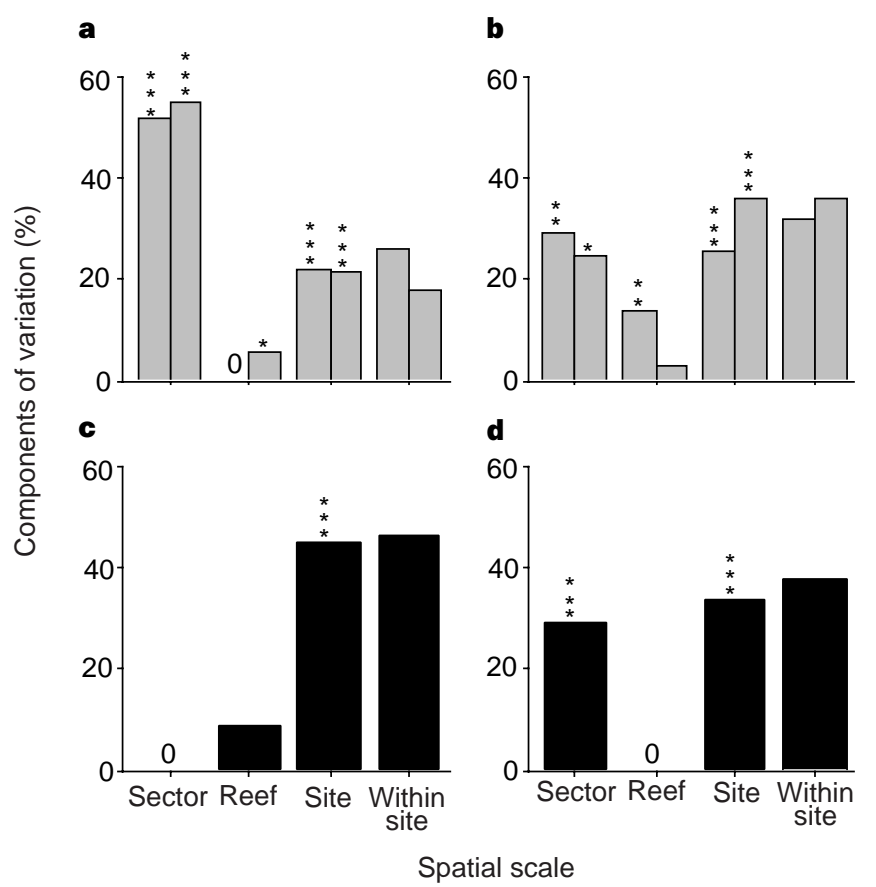

Figure 4 Components of variation at four spatial scales. Variation in numbers of $\mathbf{a}$, spawning recruits; b, brooding recruits; c, spawning adults; and d, brooding adults. The overall variation is partitioned among scales, and expressed as a percentage of the total ${ }^{10}$. Bars with asterisks indicate the spatial scales where there is significant variation, that is, where substantial differences occurred among sectors, reefs, and/or sites $\left({ }^{*}, P<0.05\right.$; $\left.{ }^{* *}, P<0.01 ;{ }^{* * *}, P<0.001\right)$. Pairs of adjoining bars for recruits in $(\mathbf{a})$ and $(\mathbf{b})$ are for two separate years, 1995/6 and 1996/7, and different reefs. that have fewer recruits. Comparative studies of recruitment and survival of reef fishes also support this hypothesis ${ }^{20,21}$. Alternatively, spatial variability in recruitment could be effectively neutralized if locations that usually have small numbers of recruits occasionally receive a much larger input. Such a scenario should produce dominant year classes within adult populations (providing that post-recruitment mortality is not strongly density dependent). However, coral populations are more typically composed of a multitude of cohorts that have accumulated over many years ${ }^{22-24}$.

Large-scale variation in recruitment has profound implications for management of coral reefs. For example, the lower recruitment rates onto Caribbean reefs are likely to result in slower rates of recovery from natural or man-made disturbances than on the $\mathrm{GBR}^{25,26}$. The high predictability in the number and cover of adult spawners at the scale of sectors and reefs on the GBR (Fig. 4) does

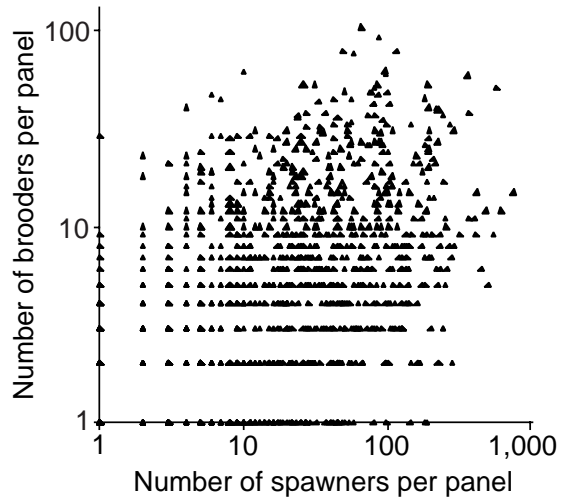

Figure 5 The correlation between recruitment of spawners and brooders (both $\log (x+1)$-transformed), plotted here at the scale of individual panels $(n=1,135$ panels for two years combined; $r=0.27, P<0.001$ ). The correlation is significant owing to the large sample size. There was only a weak correlation between the two types of recruit at any spatial scale (site, $n=127, r=0.27, P=0.002$; reef, $n=33, r=0.42, P=0.014$; sector, $n=11, r=0.53, P=0.09$ ). not mean uniformity of processes (for example, recruitment and mortality) that control abundance. We conclude that management of natural resources based on sound knowledge of process and mechanisms will be far more robust than the traditional approach that has centred on monitoring patterns of abundance.

Received 26 August; accepted 3 November 1998

1. Kareiva, P. \& Andersen, M. in Lecture Notes in Biomathematics: Community Ecology (ed. Hastings, A.) 38-45 (Springer, Berlin, 1988).

2. Wiens, J. A. Spatial scaling in ecology. Func. Ecol. 3, 385-397 (1989).

3. Jackson, J. B. C. Adaptation and diversity of reef corals. Bioscience 41, 475-482 (1991).

4. Schneider, D. C. Quantitative Ecology: Spatial and Temporal Scaling (Academic, San Diego, 1994).

5. Ricklefs, R. E. Community diversity: relative roles of local and regional processes. Science 235, $167-$ 171 (1987).

6. Levin, S. The problem of pattern and scale in ecology. Ecology 73, 1943-1967 (1992).

7. Ricklefs, R. E. \& Schluter, D. (eds) Species Diversity in Ecological Communities (Univ. Chicago Press, 1993).

8. Eberhardt, L. L. \& Thomas, J. M. Designing environmental field studies. Ecol. Monogr. 61, 53-73 (1991).

9. Harrison, P. L. \& Wallace, C. C. in Ecosystems of the World (ed. Dubinsky, Z.) 133-207 (Elsevier, New York, 1990)

10. Searle, S. R., Casella, G. \& McCulloch, C. E. Variance Components (Wiley Interscience, New York, 1992).

11. Harrison, P. L. et al. Mass-spawning in tropical reef corals. Science 223, 1186-1189 (1984).

12. Ayre, D. J. \& Dufty, S. L. Restricted gene flow in the viviparous coral Seriatopora hystrix on Australia's Great Barrier Reef. Evolution 48, 1183-1201 (1994).

13. Benzie, J. A. H., Haskell, A. \& Lehman, H. Variation in the genetic composition of coral (Pocillopora damicornis and Acropora palifera) populations from different reef habitats. Mar. Biol. 121, 731-739 (1995).

14. Ayre, D. J., Hughes, T. P. \& Standish, R. J. Genetic differentiation, reproductive mode, and gene flow in the brooding coral Pocillopora damicornis along the Great Barrier Reef, Australia. Mar. Ecol. Prog. Ser. 159, 175-187 (1997).

15. Sale, P. F., Doherty, P. J., Eckhert, G. J., Douglas, W. A. \& Ferrell, D. J. Large scale spatial and temporal variation in recruitment of fish populations on coral reefs. Oecologia 64, 191-198 (1984).

16. Doherty, P. J. \& Williams, D. McB. The replenishment of coral reef fish populations. Oceanogr. Mar. Biol. Annu. Rev. 26, 487-551 (1988).

17. Rogers, C. R., Fitz, H. C., Gilnack, M., Beets, J. \& Hardin, J. Scleractinian coral recruitment patterns at Salt River submarine canyon, St. Croix, U.S. Virgin Islands. Coral Reefs 3, 69-76 (1984).

18. Richmond, R. H. \& Hunter, C. L. Reproduction and recruitment of corals: comparisons among the Caribbean, the tropical Pacific, and the Red Sea. Mar. Ecol. Prog. Ser. 60, 185-203 (1990).

19. Smith, S. R. Patterns of coral recruitment and post-settlement mortality on Bermuda's reefs: comparisons to Caribbean and Pacific reefs. Am. Zool. 32, 663-673 (1992).

20. Sweatman, H. P. A. The influence of adults of some reef fishes on larval recruitment. Ecol. Monogr. 55, 469-485 (1985).

21. Caley, M. J. Reef-fish community structure and dynamics: an interaction between local and largerscale processes? Mar. Ecol. Prog. Ser. 129, 19-29 (1995).

22. Connell, J. H. in Biology and Geology of Coral Reefs, Vol. 1 (eds Jones, O. A. \& Endean, R. E.) 205-245 (Academic, New York, 1973). 
23. Connell, J. H., Hughes, T. P. \& Wallace, C. D. A 30-year study of coral community dynamics: influence of disturbance and recruitment on abundance, at several scales in space and time. Ecol. Monogr. 67, 461-488 (1997).

24. Hughes, T. P. Demographic approaches to community dynamics: a coral reef example. Ecology 77, 2256-2260 (1996).

25. Kojis, B. in Proc. Colloquium on Global Aspects of Coral Reefs: Health, Hazards, History (ed. R. N. Ginsburg) P35-P41 (Univ. Miami, Florida, 1993).

26. Connell, J. H. Disturbance and recovery of coral assemblages. Coral Reefs 16(Suppl.), 101-113 (1997).

Acknowledgements. We thank the 41 graduate-student volunteers from James Cook University (JCU) who provided field assistance, and D. Ayre, J. Caley, P. Doherty and L. Smith for comments on the manuscript. Research was funded by grants to T.P.H. from the Australian Research Council. This is contribution no. 162 of the Coral Group at JCU.

Correspondence and requests for materials should be addressed to T.P.H. (e-mail: terry.hughes@jcu.edu.au)

\section{Robust and optimal use of} information in stereo vision

\section{John Porrill*, John P. Frisby ${ }^{\star}$, Wendy J. Adams ${ }^{\star}$ \& David Buckley $\dagger$}

Departments of ${ }^{\star}$ Psychology and $\dagger$ Ophthalmology and Orthoptics, University of Sheffield, Sheffield S10 2TN, UK

Differences between the left and right eye's views of the world carry information about three-dimensional scene structure and about the position of the eyes in the head. The contemporary Bayesian approach to perception ${ }^{1,2}$ implies that human performance in using this source of eye-position information can be analysed most usefully by comparison with the performance of a statistically optimal observer. Here we argue that the comparison observer should also be statistically robust, and we find that this requirement leads to qualitatively new behaviours. For example, when presented with a class of stereoscopic stimuli containing inconsistent information about eccentricity of gaze, estimates of this gaze parameter recorded from one robust ideal observer bifurcate at a critical value of stimulus inconsistency. We report an experiment in which human observers also show this phenomenon and we use the experimentally determined critical value to estimate the vertical acuity of the visual system. The Bayesian analysis also provides a highly reliable and biologically plausible algorithm that can recover eye positions even before the classic stereo-correspondence problem is solved, that is, before deciding which features in the left and right images are to be matched.

To be able to specify the observer that is statistically optimal for a perceptual task ${ }^{3}$, a stochastic model of sensor noise must be available. For mathematical convenience, simple models, such as additive gaussian noise, are generally used. Although such models are adequate for describing some sources of error, most sensory data will also contain a proportion of rogue data items. It is reasonable to assume that perceptual systems have evolved to deal with this problem. We therefore introduce the idea of a robust ideal observer, that is, an observer that has optimal performance in the presence of a suitably specified population of outliers. We take this terminology from statistics, where the population mean is a simple example of a non-robust estimator and the median and mode of robust estimators. Robust and non-robust ideal observers will show quantitatively different levels of performance as the proportion of outliers increases. What is more interesting is that they can also show qualitatively different behaviour under certain experimental conditions, leading to a new type of comparison between ideal observer and human performance.

We have applied the robust ideal observer analysis to the following problem in stereo vision. The disparity in position between left and right retinal images of a point in the field of vision can be decomposed into horizontal and vertical components. The horizontal components $H$ contain information about the threedimensional structure of the world scene but they cannot be interpreted fully without knowledge of two viewing parameters that determine the positions of the eyes in the head: $g$, the gaze angle of the fixation point from the median plane of the head, and $d$, the distance to the fixation point. It is often more convenient to use the alternative dimensionless parameters ${ }^{4} \alpha=I g / d$ and $\beta=I / d$, where $I$ is the interocular separation. Because the vertical component of disparity $V$ depends to first order on only these viewing parameters and not on visual scene depths, measurements of $V$ can, in principle, be used to determine the viewing parameters and calibrate the information in $H$. We use the term $V$ analysis to describe the recovery of viewing parameters from $V$ measurements ${ }^{5-10}$

The experimental tool we used to investigate $V$ analysis is the induced effect ${ }^{11}$. This is produced when one eye's view of a frontoparallel plane is magnified in the vertical dimension. The effect is a perceived rotation of the plane about a vertical axis through an angle that is approximately proportional to the applied magnification. The size of the effect in human observers is consistent with their performing $V$ analysis to derive an incorrect eccentric gaze position and interpreting $H$ information accordingly ${ }^{6-10}$. A convenient way to measure the induced effect is to have the observer vary a second magnification applied in the horizontal dimension which also produces a perceived slant about a vertical axis, an effect called the geometric effect. The horizontal magnification can be adjusted until the geometric and induced effects cancel and the surface appears frontoparallel.

Human and ideal observer performances were compared on this nulling task. The random-dot stimuli used were designed to probe the robustness of $V$ analysis by using specified outlier populations. Half of the dots in the right image were given a vertical magnification $m$, selected from the range $0-12 \%$, and the other half were given a vertical magnification $-m / 2$ in the range $0-6 \%$. As $m$ increased, the two populations of points were therefore consistent with increasingly different viewing geometries.

Figure 1 shows Monte-Carlo simulations of the performance of a non-robust and a highly robust ideal observer on the nulling task. For an ideal observer, the nulling magnification required can be shown to equal its estimate of the viewing parameter $\alpha$, so estimated $\alpha$ values from both observers are plotted against magnification $m$

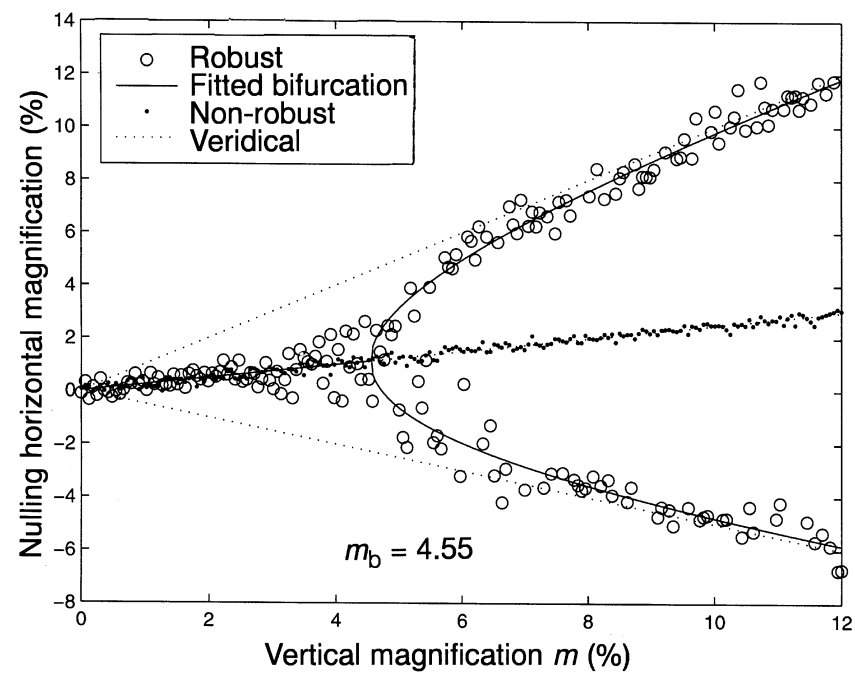

Figure 1 Monte-Carlo simulation of the performance of a non-robust and robust observer on the nulling task. The solid circles show the performance of the nonrobust observer and the open circles show that of the highly robust ideal observer. The abscissa shows the range of $m$ values used. The dotted lines show predicted induced effects $m$ and $-m / 2$ for single magnifications and for perfect pooling $(m / 4)$. The non-robust observer $\left(P=1, k=0.4^{\circ}\right)$ pools over the whole range, whereas the robust observer $(P=0.001, k=0.4)$ shows initial pooling behaviour followed by a bifurcation. Values of $P$ and $k_{30}$ were chosen to match the observed value of $m_{\mathrm{b}}$. 